\title{
Community study of depression in old age in Taiwan
}

\author{
Prevalence, life events and socio-demographic correlates \\ MIAN-YOON CHONG, CHWEN-CHENG CHEN, HIN-YEUNG TSANG, \\ TZUNG-LIEH YEH, CHENG-SHENG CHEN, YI-HUI LEE, TZE-CHUN TANG \\ and HSIN-YI LO
}

\section{Background Published studies of prevalence of depression in old age in Taiwan have yielded equivocal results.}

\begin{abstract}
Aims To study the prevalence of depressive disorders among communitydwelling elderly; further, to assess sociodemographic correlates and life events in relation to depression.
\end{abstract}

Method A randomised sample of 1500 subjects aged 65 and over was selected from three communities. Research psychiatrists conducted all assessments using the Geriatric Mental State Schedule. The diagnosis of depression was made with the GMS-AGECAT (Automated Geriatric Examination for Computerised Assisted Taxonomy); data on life events were collected with the Taiwanese version of the Life Events and Difficulties Schedule.

Results One-month prevalence of psychiatric disorders was $37.7 \%$, with 15.3\% depressive neurosis and 5.9\% major depression. A high risk of depressive disorders was found among widows with a low educational level living in the urban community, and among those with physical illnesses.

\section{Conclusions Contrary to most} previous reports, we found that the prevalence of depressive disorders among the elderly in the community in Taiwan is high and comparable to rates reported in some studies of UK samples.

Declaration of interest The National Health Research Institute of Taiwan funded this project.
Previous work on depression in old age in Taiwan and other Eastern countries emphasised lower rates of depressive illness than in Western and North American regions (Table 1). The low risk of depression in Taiwan, for example, has been explained by the positive effect of good family support systems, with a tradition of giving respect to the elderly. However, recent epidemiological studies of community subjects in Taiwan have shown that elderly people had a higher risk of minor psychiatric morbidity (Cheng, 1987; Chong, 1992). Moreover, available statistics have shown that elderly people presented a consistently increased risk of suicide (Chong \& Cheng, 1995), and many of those who died by suicide were found retrospectively to have suffered from depressive disorders (Cheng, 1995). In view of the above discrepancy, this study attempted to examine the 'true prevalence' of depression in old age in the community in Taiwan, using a rigorous epidemiological design.

\section{METHOD}

The study - the Taiwan Old Age Depression Study (TOADS) - comprised a pilot study and the main survey. The pilot study was carried out in order to test and modify the case-finding instruments, and to generate a preliminary prevalence rate for an estimation of the sample size needed for the main study.

\section{Case definition and research instruments}

Instruments used in this project include the Geriatric Mental State Schedule (GMS) and the Life Events and Difficulties Schedule (LEDS).

The GMS is a standardised, semistructured interview designed to assess psychopathology for patients over 65 years of age. It enables patients to be classified by symptom profile, and can demonstrate changes in that profile over time (Copeland et al, 1976). A community version of the GMS was derived from the parent schedule by omitting many of the items designed to tap psychotic disorders less likely to be encountered in the community; this version of the GMS has been used in European community studies (Copeland et al, 1999). The GMS was translated into Mandarin (GMS-M), and modified with colloquial terms relevant to the Taiwanese communities. Psychiatrists participating in the study had received training at the Institute of Psychiatry, London. Interrater reliability assessments of the GMS were carried out with their London colleagues and also among the eight research psychiatrists in Taiwan before the study began.

Depressive disorders and other types of psychiatric morbidity were diagnosed by means of a computer-assisted system, the Automated Geriatric Examination for Computer Assisted Taxonomy (AGECAT). Its development has been described elsewhere (Dewey \& Copeland, 1986; Copeland et al, 1986, 1999). In brief, it uses scores on the symptoms components obtained from the GMS interview described above to derive diagnostic clusters. Each subject is awarded a score $(0-4$ or $0-5)$ for each diagnostic cluster. The levels on each cluster are then compared to each other according to a hierarchy of diagnoses: organic brain syndrome, schizophrenia, mania, depression (major and neurotic), and obsessional, hypochondriacal, phobic and anxiety neuroses. The system arrives at a main diagnosis and subsidiary diagnosis. A subject who has no symptom components is referred to as 'well', while subjects with diagnostic confidence levels 1 and 2 are referred to as 'sub-cases', and those with diagnostic confidence levels 3 , 4 or 5 are 'cases'. The diagnostic agreement between the research psychiatrists and AGECAT was good, with generalised $\kappa$ scores of 0.87 for depressive disorders and 0.73 for organic brain syndrome.

The LEDS was used to collect detailed information about the occurrence and context of adverse life events during the year prior to the interview. This is a semistructured interview developed by Brown \& Harris (1978), of Bedford College, London University, for describing discrete events and ongoing long-term difficulties experienced by an individual. The Taiwanese version (LEDS-T) was modified from the original version, and each category of event or difficulty was extensively defined. The exact date of an event 
Table I Comparison between different community studies of depression in the elderly

\begin{tabular}{llcc}
\hline Authors & Site & Criteria & Prevalence (\%) \\
\hline GMS studies & & & \\
Copeland et al (1976) & Liverpool & GMS & 11.3 \\
Kay et al (1985) & Hobart & GMS & 16.1 \\
Copeland et al (1987) & New York & GMS-AGECAT & 16.2 \\
Lobo et al (1995) & Zaragoza & GMS-AGECAT & 4.8 \\
Kua et al (1996) & Singapore & GMS-AGECAT & 6.0 \\
Kirby et al (1997) & Dublin & GMS-AGECAT & 10.3 \\
Bhatnagar \& Frank (1997) & Bradford, UK & GMS-AGECAT & 20.0 \\
Newman et al (1998) & Edmonton & GMS-AGECAT & 11.2 \\
Taiwan studies & & & \\
Yeh et al (1994) & Taiwan & DIS: major depression, dysthymia & 0.5 \\
Liu et al (1997) & Kinmon, Taiwan & DSM-III-R & 0.8 \\
& & GDS & 12.9 \\
& & & 26.0 \\
\hline
\end{tabular}

GMS, Geriatric Mental State Schedule; AGECAT, Automated Geriatric Examination for Computer Assisted Taxonomy; DIS, Diagnostic Interview Schedule; GDS, Geriatric Depression Scale.

or difficulty was sought out and recorded during the interview. The degree of threat contained in each life event was rated on a four-point scale: 1 indicating 'a marked threat'; 2, 'a moderate threat'; and 4, 'little or no threat'. If an event rated moderate affected the subject, it was classified as 'an important moderately threatening event'. The interrater reliability of threat rating was satisfactory $(\kappa=0.75)$. The average annual rate of life events reported per subject was 0.8 . The mean range of uncertainty about the date of events was 2.1 weeks (s.d. $=3.8$ ); $25.5 \%$ felt certain about the exact date on which an event had occurred; $29.3 \%$ felt certain within 1 week; $17.5 \%$ felt certain within $1-2$ weeks; and $25.3 \%$ felt certain within $3-4$ weeks.

\section{Subjects}

\section{Estimation of sample size}

In the pilot study, 120 randomised subjects aged 65 and above were selected from a community. A senior psychiatrist trained in using the GMS assessed all subjects. Thirteen subjects $(10.9 \%$; $95 \%$ CI $5.3-$ $16.5)$ were diagnosed as having depressive disorders using the GMS-AGECAT system. With this estimate as a reference, an adequate sample size required for the main study was then calculated as 1485 (to achieve a power of 0.95 , with $P<0.05$ ).

\section{Study population and sampling}

Three communities - respectively from a rural (Nan-hwa), a semi-urban (Alian) and an urban location (metropolitan
Kaohsiung) in south Taiwan-were selected for the study. In order to avoid a selection bias towards underestimation of the 'true' residency of old people in these communities, the census was first consulted at the respective registration offices. It was then scrutinised for different age groups and re-checked for their residence by local officials before the study was carried out.

A random selection procedure was used to select subjects with a probability proportional to the size of the aged population studied. A multi-stage random selection was adopted in the urban community, first in selecting districts, then the $L i$ and Ling (district subdivisions in Taiwan). In the semi-urban and rural communities, randomised selection proportional to size was adopted because of the relatively smaller number of elderly in the population. For logistical reasons, a total number of 1500 subjects (500 from each community) were recruited for the main study.

\section{Data analysis}

The prevalence of all psychiatric and depressive morbidity was calculated using the GMS-AGECAT, with a $95 \%$ CI. Univariate analyses of various sociodemographic variables and life events were performed in relation to the depressive disorders, first with descriptive statistics, including odds ratio (with $95 \% \mathrm{CI}$ ). Identified significant variables were then further analysed with multivariate analyses using logistic regression (applying the likelihood ratio estimation).

\section{RESULTS}

The study was carried out between mid1996 and the end of 1998. It took a longer time than a typical community survey because of the need for careful preparation, the training of research psychiatrists, and the wide area of distribution of the subjects studied.

Altogether, 1350 (90.0\%) subjects successfully completed the interview (the respondents); $123(8.2 \%)$ subjects refused (non-respondents); and $27(1.8 \%)$ died before the interview. Most of those who died suffered from chronic physical illness related to ageing. The respondent rates were especially high in the rural $(95.6 \%)$ and semi-urban (95.4\%) communities, and somewhat lower (at $81.1 \%$ ) in the urban community.

\section{Socio-demographic characteristics of respondents}

Respondents consisted of 673 (49.9\%) males and $677(50.1 \%)$ females (Table 2$)$. Most of them $(88.9 \%)$ were ethnic Taiwanese, while $11.1 \%$ were Chinese. Males outnumbered females in the urban and suburban communities. The structure of the aged population in Taiwan is different from that in most Western countries. According to 1997 population statistics for Taiwan, there were more aged males $(8.5 \%)$ than females $(7.6 \%)$. This was due to the mass migration of Chinese soldiers from mainland China to Taiwan during the civil war in the late 1940s through the 1950s (when the Nationalist government retreated to Taiwan after the Communists took over China). Many of these Chinese resided in the urban regions and were concentrated in government quarters for the armed forces, forming an ethnicgeographical distribution distinctive to Taiwan. They represented about $30 \%$ of the sample studied in the selected urban community.

Two-thirds of the subjects $(66.1 \%)$ were aged $65-74$, while $27.3 \%$ were between 75 and 84 years old, and only $6.6 \%$ were of the 'oldest-old' group aged 85 and above. Their mean age was 73.2 years $($ s.d. $=6.2)$. There were no mean age differences among the three communities. Since this was a geriatric sample, one-third were widows/widowers. About $90 \%$ of the subjects had three or more children, and the majority $(88.5 \%)$ were living with their family. Their educational level was generally 
low (average 3.3 years). Half of them had not received any formal education, with the greater proportion in the rural and semi-urban communities. Most of those with religious beliefs practised a mixture of Buddhist and Taoist rituals.

\section{Psychiatric and physical morbidity}

Using the GMS-AGECAT system, the 1month prevalence rate of any psychiatric morbidity in this sample was found to be $37.7 \%$ (95\% CI $35.1-40.3 \%$ ). The prevalence rates of various psychiatric disorders were estimated as follows: depressive neurosis, $15.3 \%$ (95\% CI 13.4-17.3\%); organic mental disorders, $14.3 \%$ (95\% CI 12.4-16.2\%); major depression, 5.9\% (95\% CI 4.7-7.3\%); schizophrenia, 0.7\% (95\% CI $0.4-1.4 \%)$; anxiety neurosis, $0.7 \%$ (95\% CI $0.4-1.4 \%$ ); hypochondriasis, $0.5 \%$ (95\% CI $0.2-1.1 \%$ ); obsessivecompulsive disorder, $0.1 \%$ (95\% CI $0.06-$ $0.4 \%)$; and phobic neurosis, $0.1 \%(95 \%$ CI $0.06-0.4 \%$ ).

The 1-month prevalence rate of depressive disorders (major and neurotic) was estimated at $21.3 \%$ (95\% CI 19.1$23.4 \%$ ).

Among the respondents $85 \%$ had some kind of physical illness. The risk of developing depressive disorders among those with physical illness was 3.7 times $(95 \%$ CI 2.2-6.2) higher than in those without any physical problems. The physical illnesses varied, with one or more chronic illnesses such as cataract $(29.7 \%)$, arthritis $(24.4 \%)$, hypertension $(24.4 \%)$, gastro-intestinal dysfunction $(15.6 \%)$ and coronary heart disease $(12.5 \%)$. About $1 \%$ of the respondents were severely disabled and were completely dependent on care by others.

\section{Life events and depression}

From the year prior to the interview 995 events had been collected. Among these, health events $(53.9 \%)$ appeared to be the most common and the most widely experienced, followed by the death of someone with close ties (13.5\%), events connected with relationships with children and family members $(9.2 \%)$, with matters related to money or possessions $(6.2 \%)$, reproduction $(5.6 \%)$, housing $(4.7 \%)$, employment (1.6\%), and legal problems $(1.3 \%)$.

Eleven out of 287 subjects with depression - compared to 10 of 839 without any psychiatric diagnosis (non-cases) - had experienced at least one markedly threatening

Table 2 Socio-demographic characteristics of respondents

\begin{tabular}{|c|c|c|c|c|}
\hline & $\begin{array}{l}\text { Urban } \\
n(\%)\end{array}$ & $\begin{array}{l}\text { Rural } \\
n(\%)\end{array}$ & $\begin{array}{c}\text { Semi-urban } \\
n(\%)\end{array}$ & $\begin{array}{l}\text { Total } \\
n(\%)\end{array}$ \\
\hline \multicolumn{5}{|l|}{ Gender } \\
\hline Male & $212(53.7)$ & $267(56.0)$ & $194(40.6)$ & 673 (49.9) \\
\hline Female & $183(46.3)$ & $210(44.0)$ & $284(59.4)$ & $677(50.1)$ \\
\hline \multicolumn{5}{|l|}{ Age } \\
\hline $65-74$ & $253(64.1)$ & $336(70.4)$ & $303(63.4)$ & $892(66.1)$ \\
\hline $75-84$ & $|2|(30.6)$ & $109(22.9)$ & $139(29.1)$ & $369(27.3)$ \\
\hline$\geqslant 85$ & $21 \quad(5.3)$ & $32(6.7)$ & $36(7.5)$ & $89 \quad(6.6)$ \\
\hline \multicolumn{5}{|l|}{ Ethnicity } \\
\hline Taiwanese & $275(69.8)$ & $46 I(97.5)$ & 459 (96.2) & $1195(88.9)$ \\
\hline Chinese & $119(30.2)$ & $12(2.5)$ & 18 & 149 (II.I) \\
\hline \multicolumn{5}{|l|}{ Marital status } \\
\hline Never married & $9(2.3)$ & $3(0.6)$ & $13 \quad(2.7)$ & $25(1.9)$ \\
\hline Married & $235(59.5)$ & $332(70.2)$ & $28 \mathrm{I}(58.9)$ & $848(63.0)$ \\
\hline Widowed & $132(33.4)$ & $136(28.8)$ & 175 (36.7) & 443 (32.9) \\
\hline Divorced & $19(4.8)$ & $2(0.4)$ & 8 (1.7) & $29(2.2)$ \\
\hline \multicolumn{5}{|l|}{ Religion } \\
\hline Yes & $323(82.4)$ & $450(95.3)$ & 428 (89.7) & $|20|(89.6)$ \\
\hline No & $69(17.6)$ & $22(4.7)$ & $49(10.3)$ & $140(10.4)$ \\
\hline \multicolumn{5}{|l|}{ Education (years) } \\
\hline 0 & $147(37.6)$ & $234(49.5)$ & $307(64.4)$ & $688(51.3)$ \\
\hline $1-6$ & $142(36.3)$ & $186(39.3)$ & $142(29.8)$ & $470(35.0)$ \\
\hline$\geqslant 7$ & $102(26.1)$ & $53(I I .2)$ & $28 \quad(5.9)$ & $183(13.6)$ \\
\hline \multicolumn{5}{|l|}{ Living conditions } \\
\hline Alone & $48(12.2)$ & $49(10.3)$ & $58(12.2)$ & 155 (II.5) \\
\hline With family & $347(87.8)$ & $425(89.7)$ & $419(87.8)$ & II9I (88.5) \\
\hline \multicolumn{5}{|l|}{ Offspring (number) } \\
\hline 0 & $17(4.3)$ & 7 (1.5) & $17(3.6)$ & $41 \quad(3.1)$ \\
\hline $1-2$ & $58(14.7)$ & $34(7.2)$ & $35(7.3)$ & $127 \quad(9.4)$ \\
\hline $3-5$ & $222(56.3)$ & $232(49.0)$ & $227(47.6)$ & $68 \mathrm{I}(50.7)$ \\
\hline$\geqslant 6$ & $97(24.6)$ & $200(42.3)$ & $198(41.5)$ & $495(36.8)$ \\
\hline \multicolumn{5}{|l|}{ Physical illness } \\
\hline Yes & $350(88.6)$ & $382(81.1)$ & $408(85.5)$ & II $40(84.9)$ \\
\hline No & 45 (II.4) & $89(18.9)$ & $69(14.5)$ & $203(15.1)$ \\
\hline
\end{tabular}

life event in the year prior to the interview; the odds ratio (OR) was $3.30(95 \%$ CI 1.38-7.86). Life events of an important moderate or mildly threatening nature were also significantly associated with depression; their ORs were 2.94 (95\% CI 1.88 $4.60)$ and 1.93 (95\% CI 1.40-2.66), respectively. Experience of general moderate threatening life events $(\mathrm{OR}=1.47 ; 95 \% \mathrm{CI}$ 0.59-3.69) and events holding little threat $(\mathrm{OR}=1.23$; 95\% CI 0.91-1.67) were not significantly associated with depression. When the mild events were further examined, a high proportion of health events were found to be in this category. This association was insignificant after the exclusion of all mild health events in the analysis $(\mathrm{OR}=1.53$; 95\% CI 0.94-2.52).

\section{Socio-demographic factors, physical illness and depression}

Tables 3 and 4 show the relationship between individual socio-demographic factors, physical illness, life events and depressive disorders (major and neurotic). In univariate analysis (Table 3), there was a significant difference in area distribution in depressive disorders, with the trend from lower rates in rural and semi-urban communities to a much higher rate in the urban metropolis. A preponderance of depressive 
disorders was also found in females, among widows, among those with low education, and among the older ages (the 'oldestold') and in those with physical illness.

The rates of depressive disorders were 2.1 times higher in women than in men $(\mathrm{OR}=2.7 ; 95 \%$ CI 2.1-3.6; $P<0.001)$. The risk for females as against males of neurotic depression (138 v. 69; $\mathrm{OR}=2.95$; 95\% CI 2.14-4.07; $P<0.001)$ was slightly higher than of major depression (48 v. 32; $\mathrm{OR}=2.2 ; 95 \%$ CI $1.4-3.5 ; P<0.001$ ).

When the above significant factors were analysed for the risk of depressive disorders using multiple regression, it was found that female gender, low education and urban region exerted significant independent effects, while female gender and urban region demonstrated a significant interactive effect (Table 4). Age was confounded by physical illness, for older ages had a higher risk of physical illness. In summary, a high risk of depressive disorders was typically found in an urban widow with a low level of education, while those with physical illness were highly vulnerable to depression.

\section{DISCUSSION}

\section{Methodological considerations}

In studying depression among the elderly in the community, it is important to differentiate between two research strategies: studies assessing the level of symptomatology, and those using diagnostic algorithms. Most studies which assess depressed states or depressive symptoms are based on checklists or screening instruments that are sensitive to standard criteria for diagnosis of depression. However, older individuals are often afflicted by physical illnesses and disabilities, as in this study. It is not unusual for overinclusion of somatic symptoms to be found if these screening instruments are applied. In addition, although the number of depressive symptoms is an indicator of the likelihood of depression, these results are not equivalent to the diagnosis of a depressive disorder. False positives are likely with such a procedure, resulting in overestimation of the 'true' prevalence rate.

In this study trained and experienced senior psychiatrists conducted all assessments and measurements. An epidemiological study using trained psychiatrists to conduct interviews is costly, but it enables the acquisition of more reliable information than lay interviewers are able to provide, because psychiatrists have little
Table 3 Relationship between socio-demographic factors, physical illness, life events and depression: univariate analysis

\begin{tabular}{|c|c|c|c|c|}
\hline & $\begin{array}{c}\text { Depression } \\
n(\%)\end{array}$ & $\begin{array}{c}\text { Non-case } \\
n(\%)\end{array}$ & $\chi^{2}$ (d.f.) & $P$ \\
\hline Area & & & $6.537(2)$ & $<0.05$ \\
\hline Urban & $102(29.9)$ & $239(70.1)$ & & \\
\hline Semi-urban & $97(25.4)$ & $285(74.6)$ & & \\
\hline Rural & $88(21.7)$ & 317 (78.3) & & \\
\hline Gender & & & $51.107(\mathrm{I})$ & $<0.001$ \\
\hline Male & $101(16.8)$ & $50 I(83.2)$ & & \\
\hline Female & $186(35.4)$ & $340(64.6)$ & & \\
\hline Age & & & II.67| (2) & $<0.01$ \\
\hline $65-74$ & I8I (22.9) & $611(77.1)$ & & \\
\hline $75-84$ & $87(30.1)$ & $202(69.9)$ & & \\
\hline$\geqslant 85$ & $19(40.4)$ & $28(59.6)$ & & \\
\hline Ethnicity & & & $0.155(I)$ & NS \\
\hline Taiwanese & $249(25.3)$ & 737 (74.7) & & \\
\hline Chinese & $37(26.8)$ & 101 (73.2) & & \\
\hline Marital status & & & $17.339(I)$ & $<0.001$ \\
\hline Married & $160(21.6)$ & $582(78.4)$ & & \\
\hline Widowed/other & $126(33.0)$ & $256(67.0)$ & & \\
\hline Religion & & & $0.262(I)$ & NS \\
\hline Yes & $255(25.2)$ & $756(74.8)$ & & \\
\hline No & 31 (27.4) & $82(72.6)$ & & \\
\hline Education (years) & & & $32.768(2)$ & $<0.001$ \\
\hline 0 & $174(33.3)$ & $348(66.7)$ & & \\
\hline $1-6$ & $84(19.8)$ & $34 I(80.2)$ & & \\
\hline$\geqslant 7$ & $28(15.9)$ & $148(84.1)$ & & \\
\hline Living conditions & & & $1.720(\mathrm{I})$ & NS \\
\hline Alone & $37(30.3)$ & $85(69.7)$ & & \\
\hline With family & $249(24.9)$ & $753(75.1)$ & & \\
\hline Physical illness & & & $27.323(I)$ & $<0.001$ \\
\hline Yes & $268(25.4)$ & 675 (71.6) & & \\
\hline No & 18 & $163(90.1)$ & & \\
\hline Life events (threat) & & & $14.07(4)$ & $<0.005$ \\
\hline Marked & II (5.2) & $10(2.5)$ & & \\
\hline Important moderate & $4 I(19.2)$ & 45 (II.4) & & \\
\hline General moderate & $7(3.3)$ & 14 & & \\
\hline Mild & $76(35.7)$ & $132(33.3)$ & & \\
\hline Little/no & $78(36.6)$ & $195(49.3)$ & & \\
\hline
\end{tabular}

Table 4 Socio-demographic factors, physical illness and depression: multiple logistic regression

\begin{tabular}{lrccccc}
\hline Variable & B & s.e. & Wald & d.f. & $P$ & OR $(95 \% \mathrm{Cl})$ \\
\hline Constant & -1.5969 & 0.1717 & 86.5147 & $\mathrm{I}$ & $<0.000 \mathrm{I}$ & \\
Physical illness & $\mathrm{I} .4626$ & $0.338 \mathrm{I}$ & 18.7134 & $\mathrm{I}$ & $<0.000 \mathrm{I}$ & $4.3(2.2-8.4)$ \\
Education (illiterate) & $\mathrm{I} .1914$ & $0.345 \mathrm{I}$ & $\mathrm{II} .9196$ & $\mathrm{I}$ & 0.0006 & $3.3(\mathrm{I} .7-6.5)$ \\
Gender (female) & 0.8880 & 0.1687 & 27.7060 & $\mathrm{I}$ & $<0.000 \mathrm{I}$ & $2.4(\mathrm{I} .7-3.9)$ \\
Urban female & 0.8564 & 0.3206 & 7.1342 & $\mathrm{I}$ & 0.0076 & $2.3(\mathrm{I} .3-4.4)$
\end{tabular}

Physical illness dichotomised as present/absent; education dichotomised as illiterate/high; region dichotomised as urban/rural. 
difficulty in distinguishing patients with depression from normal subjects who have depressive symptoms.

The measurement of life events was carried out by means of a comprehensive, interview-based schedule, the LEDS-T. Because of the considerable length of the full and probing interview, the quality of life-event information collected is of great importance, particularly when used in a community epidemiological survey of elderly people. The results show a satisfactory interrater reliability of threat rating, a short mean range of uncertainty and limited fall-off.

High response rates were found in this study, especially in the semi-urban and rural communities. The importance of a sound response rate in any epidemiological study has long been stressed. Similarly high response rates were also noticed in epidemiological surveys of other types of psychiatric morbidity in the community in Taiwan (Cheng, 1987; Chong, 1992). They were accounted for by the close collaboration of various professions, particularly public nurses and local community officers. With their assistance and thanks to their frequent communication with the subjects and their families, high response rates were able to be achieved. Besides, because interviews were conducted at temples that also served as community centres in some villages, subjects were more likely to cooperate and provide reliable information.

\section{Prevalence studies}

A high prevalence rate of depression in old age was found in this study, which contradicted the findings of most previous studies in Taiwan (Table 1) and other Oriental countries (Komahashi et al, 1994; Kua et $a l, 1996)$, where lower rates have long been emphasised. Comparison with these studies is difficult, because of differences in research methodology, diagnostic criteria and instruments used.

In general, significantly lower rates of depression were found in a study employing lay interviewers to collect information using the Diagnostic Interview Schedule (DIS) (Yeh et al, 1994). The DIS is based on the criteria of DSM-III (American Psychiatric Association, 1980), which require high specificity. This is appropriate for biological research but not suitable in a community survey where high sensitivity is needed to identify cases for treatment. This being so, it is not surprising that studies using the DIS in community surveys generally demonstrated consistently lower rates than most studies with other standardised instruments.

When comparing different studies using the GMS, it was found that the prevalence rate of depression in old age in this study is comparable to that recorded in a recent report on migrants from the Indian subcontinent living in Bradford, UK (Bhatnagar \& Frank, 1997), but higher than those reported from Liverpool (Copeland et al, 1976), Dublin (Kirby et al, 1997) and other European (Beekman et al, 1999) and most Asian studies. Moreover, the prevalence rate of depression in old age is three times higher than that reported from Singapore (Kua et al, 1996), a community composed predominantly of ethnic Chinese. There were, however, great differences in rates of suicide between Singapore and Taiwan, with a higher rate as well as a trend of higher suicidal risk with age in Taiwan (Kok \& Tseng, 1992; Chong \& Cheng, 1995). The high rate of depression in this study is also comparable to that shown in a recent study using the Geriatric Depression Scale (Brink et al, 1982) in Kimen, an island just off the coast of mainland China, which is populated by Chinese (Liu et al, 1997).

\section{Socio-demographic correlates of depression}

\section{Gender}

Depressive symptomatology in late life is usually found to be more prevalent among women than men. This gender difference has also been established in most general population surveys (Cheng, 1989) and clinical settings. The excess rate had been accounted for by the finding that women were more likely to detect and report depressive symptoms than men. These symptoms are more frequently observed in a clinical setting, where it is culturally and logically more acceptable to express distress in somatic form. In this study, experienced psychiatrists carried out all the assessments, and for them it was not difficult to differentiate a functional symptom from one denoting physical illness. On the other hand, most subjects were able to express their distress eloquently in colloquial Taiwanese terms, such as kan-kor (emotional distress), ul-juit (depression) or funlow (upset). The risks of depressive disorders in this study, leaving aside the benefits of better reporting or detection, were, however, twice as high in women than in men. A similar gender ratio distribution was also seen in other surveys of minor psychiatric morbidity in Taiwan (Cheng, 1987; Chong, 1992).

\section{Marital status}

The relation of marital status to depression among elderly people is less controversial. It is generally believed that depression associated with widowhood is probably due to the bereavement. In addition, loneliness, one of the depressive manifestations, is commonly seen in elderly people regardless of their marital status.

\section{Education and social environment}

A high risk of depression was found among the elderly of a lower educational level. Education is one of the general criteria in the assessment of socio-economic status, besides job and income. The educational level of the subjects in this study sample was generally low, with more than half being illiterate. Their low level of education was accounted for by the unpopularity of formal education during their childhood, a time when China was war-torn and when Taiwan was under Japanese control (1895-1945). It is well established that low socio-economic status is frequently associated with poor health, a condition related to depression.

Despite the vast social and economic transformation that has taken place in Taiwan in recent decades, social welfare for the elderly is still inadequate and far below that in most industrialised countries. Many of the elderly are looked after by family members, predominantly sons, who take their share in turn. Taking care of the elderly has become a burden for poor families, who are generally of a low educational level. In the urban community, where a higher risk of depression was found, limitations in the number of rooms and restrictions on movement for the elderly were noticed. By contrast, in the rural areas, healthy old couples were seen living together, in their own house and on their own land, carrying out light farm work. Communication with their children was maintained by telephone. Thus the support and daily activities as well as the mental health of elderly people in the rural community are extended. 


\section{Physical morbidity and other life events}

Health difficulties exhibited the highest risk for depressive disorders in this crosssectional study - more than any other single socio-demographic factor. The majority of the incidences of physical morbidity in this sample were chronic illnesses. Having a health problem is in itself stressful. It may lead to disability and impairment, which contribute to the onset and continuance of late-life depression (Henderson et al, 1997; Prince et al, 1998). This finding is compatible with those of other community studies, where poor health and disability accounted for $35 \%$ of the total variance in depression and outranked demographic, social support and life events (Kennedy et al, 1989). High physical morbidity in this sample might contribute to the high rates of depression, which most previous studies in Taiwan did not address.

Health problems, difficulties in relationships and financial problems were the three main stressful life events. Similar findings were also noted in a survey in another Chinese community (Boey \& Chi, 1998). Relationship problems, particularly those regarding children or daughters-in-law, are significant in the Chinese family. Financial difficulty is very much correlated with the quality of life. During the period of the study, some local governments in Taiwan, including those of the communities from which our study samples were drawn, initiated monthly subsidiary benefits for the elderly. These benefits, despite their relatively small amounts, were substantially significant for those in need. Support from both the family and community are thus essential for the mental health of the elderly.

\section{ACKNOWLEDGEMENTS}

The authors thank Professor Anthony Mann of the Institute of Psychiatry, London, Professor Tsung-Yi Lin of the University of British Columbia, Canada, and Professor Andrew Cheng of the Institute of Biomedical Sciences, Academia Sinica, Taiwan, for their invaluable advice and supervision. We are obliged to the public health nurses and local officers who helped to locate subjects in this study, and most of all, we are grateful to all the respondents and their families for their cooperation and for making this study a success. The study was conducted under a grant from the National Health Research Institute, Taiwan (85-CNT-MD-50IP DDOI-86IX-MD50IP).

\section{CLINICAL IMPLICATIONS}

- The prevalence rate of depressive disorders among the elderly in Taiwan is as high as rates reported in the West.

Health problems were the main stressful life events experienced by the elderly.

- Being female, a widow, with low education and physical morbidity gave high risks for depression in the elderly.

\section{LIMITATIONS}

Prevalence of sub-threshold depression was not addressed.

Organic brain disorders with depression were excluded in the analysis.

No further cross-comparison among different studies was attempted.

MIAN-YOON CHONG, MRCPsych, HIN-YEUNG TSANG, MD, CHENG-SHEN CHEN, MD, TZE-CHUN TANG, MD, Department of Psychiatry, Kaohsiung Medical University, Kaohsiung, Taiwan; CHWEN-CHENG CHEN, MRCPsych, TZUNG-LIEH YEH, MD, YI-HUI LEE, MD, HSIN-YI LO, MD, Department of Psychiatry, National Cheng Kung University, Tainan, Taiwan

Correspondence: Dr Mian-Yoon Chong, Associate Professor and Director, Department of Psychiatry, Kaohsiung Medical University, 100 Shih-Chuan First Road, Kaohsiung 807, Taiwan. Tel: 8867 3208219; fax: 8867 3II2492; e-mail: mchong@cc.kmu.edu.tw

(First received 4 November 1999, final revision 25 April 2000, accepted 19 June 2000)

\section{REFERENCES}

American Psychiatric Association (1980) Diagnostic and Statistical Manual of Mental Disorders (3rd edn) (DSM-III). Washington, DC: APA

Beekman, A. T. F., Copeland, J. R. M. \& Prince, M. J. (1999) Review of community prevalence of depression in later life. British Journal of Psychiatry, 174, 307-3II.

Bhatnagar, K. \& Frank, J. (1997) Psychiatric disorders in elderly from the Indian sub-continent living in Bradford. International Journal of Geriatric Psychiatry, 12, 907-912

Boey, K.W. \& Chi, I. (1998) A study of life events and psychological well-being of the older adults in Hong Kong. Journal of Clinical Geropsychology, 4, 55-64.

Brink, T. L., Yesavage, J. A., Lum, O., et al (1982) Screening tests for geriatric depression. Clinical Gerontologist, I, 37-43.

Brown, G.W. \& Harris, T. O. (1978) Social Origins of Depression: A Study of Psychiatric Disorder in Women. London: Routledge.

Cheng, T. A. (1987) A Community Study of Minor Psychiatric Morbidity in Taiwan. PhD thesis, University of London.

- (1989) Sex differences in prevalence of minor psychiatric morbidity: A social epidemiological study in Taiwan. Acta Psychiatrica Scandinavica, 80, 395-407.

- (1995) Mental illness and suicide. Archives of General Psychiatry, 52, 594-603.

Chong, M.Y. (1992) The Six-year Follow-up Study of Minor Psychiatric Morbidity in the Community in Taiwan. $\mathrm{PhD}$ thesis, University of London.
_ \& Cheng, T. A. (1995) Suicidal behaviour observed in Taiwan: Trends over four decades. In Chinese Society and Mental Health (eds T. Y. Lin,W. S. Teng \& E. K. Yeh), pp. 209-218. Hong Kong: Oxford University Press.

Copeland, J. R. M., Kelleher, M. J., Kellett, J. M., et a (1976) A semi-structured clinical interview for the assessment of diagnosis and mental state in the elderly: The Geriatric Mental State Schedule. I. Development and reliability. Psychological Medicine, 6, 439-449.

\section{— , Dewey, M. E. \& Griffiths-Jones, H. M. (1986)}

Computerized psychiatric diagnostic system and case nomenclature for elderly subjects: GMS and AGECAT. Psychological Medicine, 16, 89-99.

_ , _ , Wood, N., et al (1987) Range of mental illness among the elderly in the community. Prevalence in Liverpool using the GMS-AGECAT package. British Journal of Psychiatry, I50, 8I5-823.

_, Beekman, A. T. F., Dewey, M. E., et al (1999) Depression in Europe. Geographical distribution among older people. British Journal of Psychiatry, 174, 312-321.

Dewey, M. E. \& Copeland, J. R. M. (1986)

Computerized psychiatric diagnosis in the elderly: AGECAT. Journal of Microcomputer Applications, 9 135-140.

Henderson, A. S., Korten, A. E., Jacomb, P. A., et a (1997) The course of depression in the elderly: a longitudinal community-based study in Australia. Psychological Medicine, 27, 119-129.

Kay, D. W. K., Henderson, A. S., Scorr, R., et al (1985) Dementia and depression among the elderly living in the Hobart community: the effect of diagnostic criteria on 
the prevalence rates. Psychological Medicine, $\mathbf{1 5}$, 77I-778.

Kennedy, G. J., Kelman, H. R., Thomas, C., et al (1989) Hierarchy of characteristics associated with depressive symptoms in an urban elderly sample. American Journal of Psychiatry, 2, 220-225.

Kirby, M., Bruce, I., Radic, A., et al (1997) Mental disorders among the community-dwelling elderly in Dublin. British Journal of Psychiatry, I7I, 369-372.

Kok, L. P. \& Tseng, W. S. (1992) Suicidal Behaviour in the Asia-Pacific Region. Singapore: Singapore University Press.

Komahashi, M., Ohmori, K. \& Nakano, T. (1994)

Epidemiological survey of dementia and depression among the aged living in the community in Japan Japanese Journal of Psychiatry and Neurology, 48, 517-526.

Kua, E. H., Ko, S. M., Fones, S. L. C., et al (1996) Comorbidity of depression in the elderly - an epidemiological study in a Chinese community International Journal of Geriatric Psychiatry, II, 699-704.

Liu, C. Y., Wang, S. J., Teng, E. L., et al (1997)

Depressive disorders among older residents in

Chinese rural community. Psychological Medicine, 27. 943-949.

Lobo, A., Saz, P., Marcos, G., Dia, J-L., et al (1995)

The prevalence of dementia and depression in the elderly community in a southern European population: the Zaragoza study. Archives of General Psychiatry, 52. 497-506.
Newman, S. C., Sheldon, C.T. \& Bland, R. C. (1998) Prevalence of depression in an elderly community sample: a comparison of GMS-AGECAT and DSM-IV diagnostic criteria. Psychological Medicine, 28, 1339-1345.

Prince, M. J., Harwood, R. H., Thomas, A., et al (1998) A prospective population-based cohort study of the effects of disablement and social milieu on the onset and maintenance of late-life depression. The Gospel Oak Project VII. Psychological Medicine, 28, 337-350.

Yeh, E. K., Hwu, H. K., Chang, L. Y., et al (1994) Mental disorders and cognitive impairment among the elderly community population in Taiwan. In Principles and Practice of Geriatric Psychiatry (eds J. R. M. Copeland M. T. Abou-Saleh \& D. G. Blazer), pp. 865-87I. London: John Wiley \& Sons. 